\title{
Acute myeloid leukemia: negative prognostic impact of early blast persistence can be in part overcome by a later remission prior to post-induction therapy
}

\begin{abstract}
Jana Ihlow, ${ }^{1,2}$ Sophia Gross, ${ }^{1}$ Leonie Busack, ${ }^{1}$ Anne Flörcken,,3 Julia Jesse, ${ }^{1}$ Michaela Schwarz, ${ }^{1}$ Nina Rosa Neuendorff, ${ }^{1}$ Ann-Christin von Brünneck, ${ }^{2}$ Ioannis Anagnostopoulos, ${ }^{2}$ Seval Türkmen, ${ }^{3,4}$ Igor Wolfgang Blau, ${ }^{1,3}$ Thomas Burmeister, ${ }^{1,3}$ David Horst, ${ }^{2}$ Lars Bullinger ${ }^{1,3}$ and Jörg Westermann ${ }^{1,3}$
\end{abstract}

1'Department of Hematology, Oncology and Tumor Immunology, Campus Virchow Clinic, Charité-Universitätsmedizin Berlin, corporate member of Freie Universität Berlin and Humboldt-Universität zu Berlin; ${ }^{2}$ Institute of Pathology, Charité-Universitätsmedizin Berlin, corporate member of Freie Universität Berlin and Humboldt-Universität zu Berlin; ${ }^{3}$ Labor Berlin Charité Vivantes GmbH and ${ }^{4}$ Department of Medical Genetics and Human Genetics, Charité-Universitätsmedizin Berlin, corporate member of Freie Universität Berlin, Humboldt-Universität zu Berlin, Berlin, Germany
Correspondence:

Jörg Westermann

joerg.westermann@charite.de

Received: $\quad$ May 2, 2021.

Accepted: $\quad$ October 7, 2021.

Prepublished: November 11, 2021

https://doi.org/10.3324/haematol.2021.279134

(2022 Ferrata Storti Foundation

Haematologica material is published under

a CC-BY-NC license @@ $\Theta$

\begin{abstract}
In acute myeloid leukemia, there is an ongoing debate on the prognostic value of the early bone marrow assessment in patients receiving intensive therapy. In this retrospective study, we analyzed the prognostic impact of the early response in 1,008 patients with newly diagnosed acute myeloid leukemia, who were treated at our institution with intensive chemotherapy followed by consolidation chemotherapy and/or allogeneic hematopoietic stem cell transplantation (HSCT). We found that early blast persistence has an independent negative prognostic impact on overall survival, eventfree survival and relapse-free survival. This negative prognostic impact may only be overcome in patients showing at least a partial remission at the early bone marrow assessment and who subsequently achieve blast clearance by additional induction chemotherapy prior to consolidation therapy with allogeneic HSCT. In accordance, we propose that the time slope of remission is an additional leukemia-related dynamic parameter that reflects chemosensitivity and thus may inform post-induction therapy decision-making. In addition to patient-related factors, European LeukemiaNet risk group, measurable residual disease monitoring and donor availability, this may particularly apply to European LeukemiaNet intermediate-risk patients, for whom a decision between consolidation chemotherapy and allogeneic HSCT remains challenging in many cases.
\end{abstract}

\section{Introduction}

In acute myeloid leukemia (AML), an early bone marrow (BM) assessment is widely performed during the induction therapy to guide further decisions regarding therapy. ${ }^{1-4}$ However, a clear consensus concerning its prognostic impact on long-term survival and the optimal time point to perform an early BM assessment does not exist so far. ${ }^{1,3,5-11}$ While several studies negate the prognostic value of an early BM assessment, ${ }^{8,9,11}$ many others discuss early blast clearance as a favorable prognostic parameter with regard to both remission rates and longterm survival..$^{1,2-14}$ Conversely, early blast persistence has been linked to an unfavorable outcome in patients treated intensively for AML. ${ }^{10,12,13,15}$ However, it is still unclear whether a potential negative prognostic impact of early blast persistence can be overcome during subsequent therapy of AML.

The present study was conducted in a large cohort of intensively treated AML patients $(n=1,008)$ with the aims of (i) analyzing the prognostic impact of early blast clearance on overall survival (OS), event-free survival (EFS) and relapse-free survival (RFS), and (ii) of evaluating the longterm prognosis in patients with early blast persistence.

\section{Methods}

Clinical characteristics, treatment and endpoints We have treated 1,340 patients aged $\geq 18$ years with newly diagnosed AML at our clinic within the past two decades (January $1^{\text {st }}, 2000$ - December $31^{\text {st }}, 2018$ ). After application 
of the exclusion criteria (Figure 1), 1,008 patients were eligible for this retrospective and non-interventional study, which is in line with local ethical guidelines and the Declaration of Helsinki and was approved by the local ethics committee (EA1/038/21).

Standard first-line induction therapy consisted of cytarabine-/daunorubicin-based chemotherapy according to the "7+3" regimen. Some patients received comparable induction therapy with Idarubicin, cytarabine and etoposide (ICE), thioguanine, cytarabine and daunorubicin (TAD9) or high-dose cytarabine and mitoxantrone (HAM) within particular clinical trial protocols. Targeted therapies such as midostaurin or gemtuzumab-ozogamicin were applied in some patients in addition to " $7+3$ "-based regimens within clinical trials. Consolidation chemotherapy was performed with intermediate- to high-dose cytarabine-based therapy with or without mitoxantrone or TAD9 in particular clinical trials (more details concerning chemotherapy are provided in the Online Supplementary Methods). Allogeneic hematopoietic stem cell transplantation (HSCT) following either myeloablative (MAC) or reduced-intensity conditioning $(\mathrm{R} I \mathrm{C})$ regimens was used as consolidation therapy in first remission or in relapsed/refractory patients (further details are given in the Online supplementary Methods).

BM assessment was performed at baseline, on day 14-21 of the first induction cycle, and prior to post-induction therapy. BM assessment was performed by both morphology (cytology and/or histopathology) and multiparametric flow cytometry (see Online supplementary Methods). The 2010 European LeukemiaNet (ELN) classification was applied for the assessment of the remission status (see Online Supplementary Methods). ${ }^{16}$ For this analysis, combined remission was defined as a combination of complete remission plus complete remission with incomplete hematologic recovery plus morphological leukemia-free state (MLFS). Early partial remission (PR) was defined by a decrease of bone marrow blasts by at least $50 \%$ to a blast percentage in the range of $5 \%-25 \%$. Cytogenetic and molecular risk was defined using the ELN risk stratification of 2010 (due to a lack of some molecular data that are mandatory for the 2017 ELN risk classification).$^{16}$ The patients' general condition was measured by the Eastern Cooperative Oncology Group (ECOG) performance score. ${ }^{17}$ Comorbidity was assessed using the Charlson Comorbidity Index. ${ }^{18}$ OS, EFS, RFS, risk of relapse and non-relapse mortality were defined as clinical endpoints by applying the Cheson criteria and the response criteria of the European Society for Blood and Bone Marrow Transplantation..$^{19,20}$

\section{Statistical analysis}

Data were curated and retrospectively analyzed using SPSS 23.0 software $\left(\right.$ IBM $^{\circledR}, 2015$, Armonk, NY, USA).

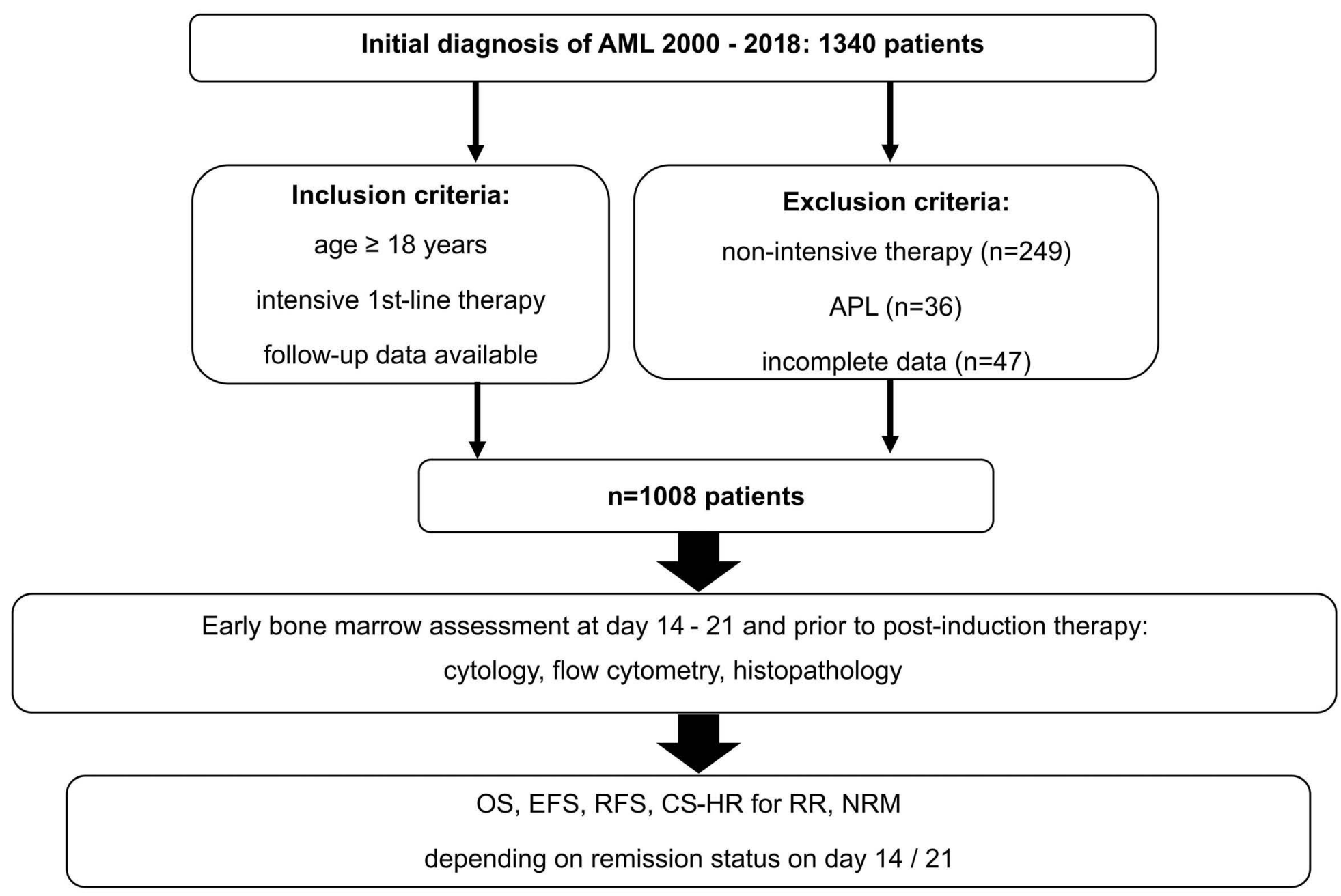

Figure 1. Study design and clinical endpoints. AML: acute myeloid leukemia; APL; acute promyelocytic leukemia; OS: overall survival; EFS: event-free survival; RFS: relapse-free survival; CS-HR: cause-specific hazard ratio: RR: risk of relapse; NRM: nonrelapse mortality. 
Baseline characteristics were analyzed using the Kruskal-Wallis-H test and the $\chi^{2}$ test followed by post-hoc testing and Bonferroni adjustment. The median followup was estimated by the reverse Kaplan-Meier method. Survival was analyzed by the Kaplan-Meier method. The log-rank test was used to detect survival differences between groups. Subsequently, univariate and multivariate Cox regression models, which included factors with a significance level of $P \leq 0.1$, were applied. In order to define a hazard ratio (HR) and a cause-specific hazard ratio (CS-HR), the variables were transformed into categorical dichotomous data. To estimate the relapse risk and non-relapse mortality in patients with blast clearance, a multivariate cause-specific Cox proportional hazards model that included confounding factors with a significant impact on relapse and survival was used based on an etiological approach. Within this model, death and relapse were defined as competing events and hence treated as censored observations. ${ }^{21}$ Post-hoc survival analysis was conducted using the Benjamini-Hochberg procedure. A $P<0.05$ was considered statistically significant. For graphical presentation, Graph Pad Prism 8 (GraphPad Software.Inc) was applied.

Table 1. Baseline characteristics and therapeutic approach in 1,008 acute myeloid leukemia patients with regard to remission status at interim bone marrow assessment.

\begin{tabular}{|c|c|c|c|c|}
\hline Characteristics & $\begin{array}{l}\text { Early blast } \\
\text { clearance }\end{array}$ & Early PR & $\begin{array}{l}\text { Early resistant } \\
\text { AML }\end{array}$ & P-value \\
\hline N (\% entire cohort) & $572(57)$ & 196 (19) & $240(24)$ & \\
\hline ECOG, median (IQR) & $1(0-1)$ & $0(0-1)$ & $0(0-1)$ & 0.144 \\
\hline CCI, median (IQR) & $0(0-1)$ & $0(0-1)$ & $0(0-1)$ & 0.237 \\
\hline Age (years), median (IQR) & $56(46-64)$ & $54(43-61)$ & $57(45-65)$ & 0.060 \\
\hline $\begin{array}{l}\text { Subtype of AML } \\
\text { de novo AML, N (\% remission subgroup) } \\
\text { sAML, N (\% of remission subgroup) } \\
\text { tAML, N (\% of remission subgroup) } \\
\text { unknown, N (\% of remission subgroup) }\end{array}$ & $\begin{array}{l}387(68) \\
115(20) \\
67(11) \\
3(1)\end{array}$ & $\begin{array}{c}136(69) \\
42(22) \\
16(8) \\
2(1)\end{array}$ & $\begin{array}{l}137(57) \\
74(31) \\
26(11) \\
3(1)\end{array}$ & 0.019 \\
\hline $\begin{array}{l}\text { ELN } 2010 \text { risk group } \\
\text { favorable, } \mathrm{N} \text { (\% of remission subgroup) } \\
\text { intermediate I/II, N (\% of remission subgroup) } \\
\text { adverse, } \mathrm{N} \text { (\% of remission subgroup) } \\
\text { unknown, } \mathrm{N} \text { (\% of remission subgroup) }\end{array}$ & $\begin{array}{l}97(17) \\
280(49) \\
121(21) \\
74(13)\end{array}$ & $\begin{array}{l}19(10) \\
96(49) \\
67(34) \\
14(7)\end{array}$ & $\begin{array}{c}8(3) \\
123(51) \\
90(38) \\
19(8)\end{array}$ & $<0.001$ \\
\hline $\begin{array}{l}\text { Allo-HSCT in } 1^{\text {st }} \text { remission, } \mathrm{N} \text { (\% of remission subgroup) } \\
\text { double induction prior to allo-HSCT, N (\% allo-HSCT } \\
1^{\text {st }} \mathrm{CR} / \mathrm{CRi} / \mathrm{MLFS} \text { within remission subgroup) }\end{array}$ & $\begin{array}{l}225(39) \\
120(53)\end{array}$ & $86(44)$ & $90(38)$ & $0.423^{*}$ \\
\hline $\begin{array}{l}\text { consolidation chemotherapy prior to allo-HSCT } \\
\mathrm{N} \text { (\% allo-HSCT } 1^{\text {st }} \mathrm{CR} / \mathrm{CR} \text { /MLFS within remission } \\
\text { subgroup) }\end{array}$ & $158(70)$ & $53(62)$ & $49(54)$ & $0.230^{\star}$ \\
\hline $\begin{array}{l}\text { Allo-HSCT in } 2^{\text {nd }} \text { remission or as salvage therapy, N (\% } \\
\text { of remission subgroup) }\end{array}$ & $156(27)$ & $63(32)$ & $67(28)$ & $0.317^{\star}$ \\
\hline $\begin{array}{l}\text { Consolidation chemotherapy without allo-HSCT, N (\% of } \\
\text { remission subgroup) }\end{array}$ & $191(33)$ & $47(24)$ & $83(35)$ & $0.070^{*}$ \\
\hline $\begin{array}{l}\text { double induction prior to scheduled consolidation } \\
\text { chemotherapy, N (\% of non-allo-HSCT within } \\
\text { remission subgroup) }\end{array}$ & $87(46)$ & $38(81)$ & $59(71)$ & $0.021^{*}$ \\
\hline $\begin{array}{l}\text { CR/CRi/MLFS after double induction, } \mathrm{N} \text { (\% of all non- } \\
\text { allo-HSCT patients with double induction) }\end{array}$ & $69(79)$ & $29(76)$ & $29(49)$ & $0.045^{\star}$ \\
\hline
\end{tabular}




\section{Results}

\section{Clinical characteristics}

A total of 1,008 patients, who had undergone intensive therapy, were eligible for this analysis. The median followup was 63.1 months (95\% confidence interval [95\% Cl]: 55.3-71.0 months). Fifty-seven percent of the entire cohort showed early blast clearance $(n=572)$, whereas $43 \%$ had blast persistence $(n=436)$. Within the latter group, $45 \%$ (196/436) had an early PR and 55\% (240/436) showed early resistant disease without any response. The distribution of baseline characteristics within the entire cohort and the three "remission groups" (early blast clearance, early $\mathrm{PR}$ and early resistant $\mathrm{AML}$ ) are shown in Table 1. As expected, ELN risk stratification $(P<0.001)$ and subtype of $A M L$ differed significantly between the three groups $(P=0.019)$. However, there were no further significant differences with regard to baseline characteristics. The further treatment of patients with early blast persistence beyond induction 1 is outlined in Table 1 and Figure 2.

\section{Early blast clearance and early blast persistence are prognostic in the entire cohort}

The entire cohort had a 5 -year os of $35 \%$ with a median OS of 28.5 months ( $95 \% \mathrm{Cl}: 24.4$ - 32.6 months). The evaluation of early BM results revealed a significant decrease in OS in patients with early blast persistence as compared to those with blast clearance $(P<0.001)$ (Table
2). The 5-year OS of patients with early blast clearance was $41 \%$ as compared to $30 \%$ for those with early blast persistence $(P<0.001)$. This observation maintained its significance within a multivariate model $(H R=1.4, P<0.001)$ (Table 2) that included all factors with a significant impact on survival within the univariate analysis (ECOG status $>1$ : $P=0.004$; Charlson Comorbidity Index $\geq 2$ : $P=0.003$; ELN risk group intermediate/adverse: $P<0.001$ (including FLT3ITD mutational status); age $\geq 60$ years: $P<0.001$; and subtype of AML: $P<0.001)$.

In the entire cohort, 5-year EFS and RFS were $24 \%$ and 25\%. The median EFS and RFS were 13.9 months (95\% Cl: 12.4-15.5 months) and 13.9 months (95\% Cl: 11.9-15.9 months), respectively. The negative prognostic impact of early blast persistence also translated into an effect on EFS. Early blast clearance was associated with a 5-year EFS of $26 \%$ as compared to $18 \%$ in patients with early blast persistence $(P=0.001)$ (Table 2$)$. This significant difference was also maintained within the multivariate analysis $(H R=1.3, P=0.001)$. Comparable results were observed for RFS with a hazard ratio of 1.2 in the multivariate analysis in the presence of the other biologically relevant risk factors that are mentioned above $(P=0.031)$ (Table 2).

The negative prognostic impact of early blast persistence can be overcome if a response is achieved prior to post-induction therapy

In the entire cohort, the combined remission rate was $81 \%$

\section{Treatment for AML patients with early blast persistence}

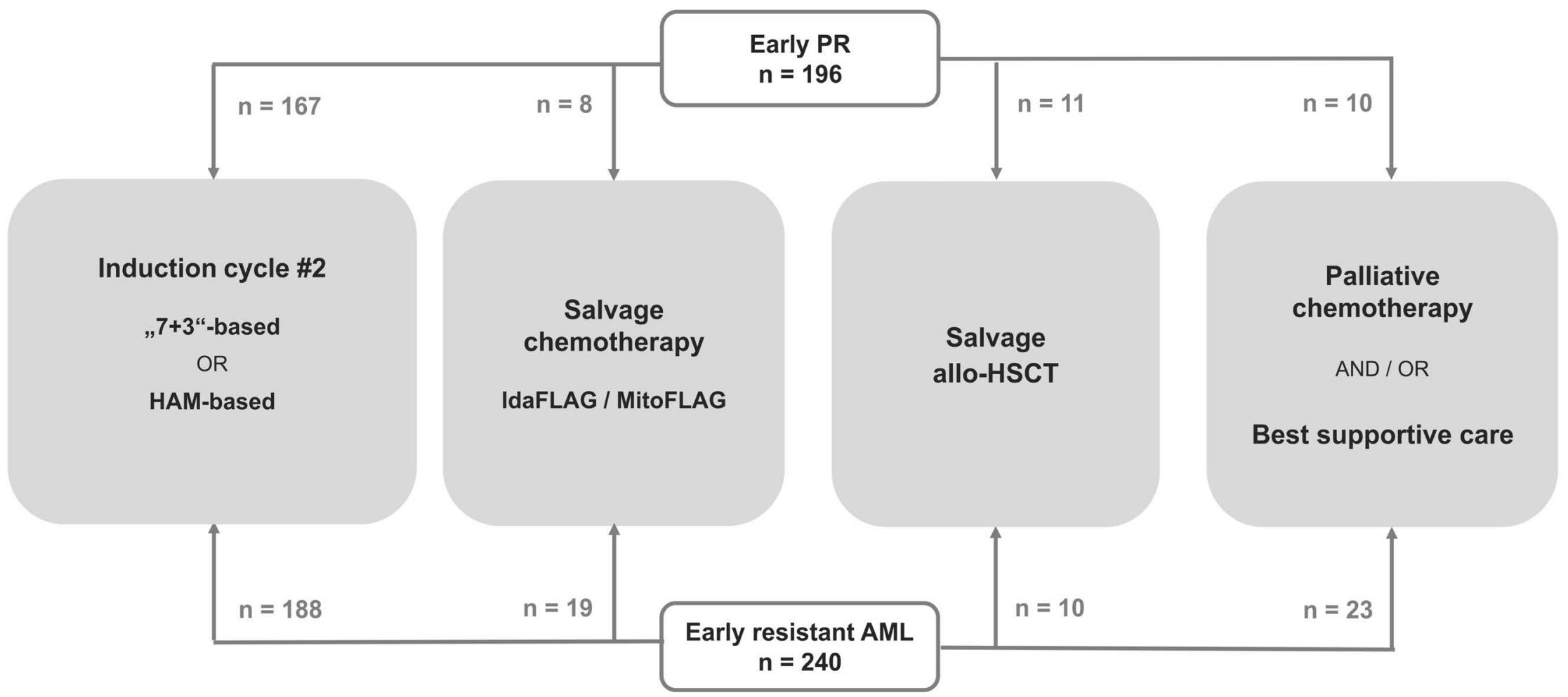

Figure 2. Further treatment in $\mathbf{4 3 6}$ acute myeloid leukemia patients with early blast persistence. For further details regarding chemotherapy, see the Online Supplementary Methods. AML: acute myeloid leukemia; PR: partial remission; n: number of patients; "7+3": cytarabine-/daunorubicin-based chemotherapy according to the "7+3" regimen; HAM: high-dose cytarabine and mitoxantrone; IdaFLAG: idarubicin, fludarabine, cytarabine; granulocyte colony-stimulating factor; MitoFLAG: mitoxantrone, fludarabine, cytarabine; granulocyte colony-stimulating factor; allo-HSCT:, allogeneic hematopoietic stem cell transplantation. 
$(813 / 1,008)$ prior to scheduled post-induction therapy. The combined remission rate was $89 \%(508 / 572)$ in patients with early blast clearance and $70 \%$ (305/436) in patients with early blast persistence after additional therapy $(P<0.001)$. The negative prognostic impact of early blast persistence was maintained in patients who achieved blast clearance during further induction therapy. The 5year OS and RFS were $43 \%$ and $26 \%$ in patients with an early blast clearance as compared to $31 \%$ and $23 \%$ in patients with early blast persistence who achieved a remission prior to post-induction therapy $(P=0.016$ and $P=0.013$ ) (Table 2). The negative prognostic impact of early blast persistence was also maintained in the multivariate model that included relevant risk factors for OS $(H R=1.3$, $P=0.024)$ and RFS (HR=1.4, $P=0.002)$ (Table 2). Furthermore, patients with early blast persistence showed an increased risk of relapse in the cause-specific hazard model which included the same covariates (CS-HR=1.3,
$P=0.039$ ) (Table 2). Moreover, in patients with early blast persistence, there was a strong trend towards a higher risk of non-relapse mortality, even in the presence of other risk factors (CS-HR=1.4, $P=0.069$ ) (Table 2). Interestingly, in the group with early blast persistence, survival was very heterogeneous depending on whether the patients had at least an early PR or showed early resistant disease (Figure 3). The survival of patients with early PR and subsequent combined remission prior to consolidation therapy was comparable to the survival of patients with early blast clearance (5-year OS: 45\% vs. 44\%, $P=0.618$ ), whereas early resistant $A M L$ maintained its negative prognostic impact throughout the analysis (5year OS: $28 \%, P<0.001)$. Comparable results were observed for RFS (Figure 3). Similarly, early resistant AML (but not early PR) remained prognostically unfavorable in the multivariate analysis for both OS ( $\mathrm{HR}=1.5,95 \% \mathrm{Cl}: 1.2-$ 2.0; $P=0.001)$ and $\mathrm{RFS}(\mathrm{HR}=1.4,95 \% \mathrm{Cl}: 1.1-1.7 ; P=0.012)$.

Table 2. Impact of early blast persistence on survival in the entire cohort and in patients with combined remission prior to consolidation therapy.

\begin{tabular}{|l|c|c|c|}
\hline Survival & Early blast clearance & $\begin{array}{c}\text { Early blast persistence } \\
\text { (PR \& resistant AML) }\end{array}$ & P-value \\
\hline
\end{tabular}

\section{Entire cohort}

$\mathrm{N}$ (\% entire cohort)

$572(57)$

436 (43)

OS (months), median $(95 \% \mathrm{Cl})$

35.8 (29.4-42.3)

$18.0(14.2-21.8)$

$<0.001$

RFS (months), median $(95 \% \mathrm{Cl})$

15.7 (13.2-18.2)

$11.5(9.1-13.9)$

0.100

EFS (months), median (95\% Cl)

$16.2(13.8-18.6)$

$11.3(10.0-12.6)$

0.001

MV-HR* for OS with early blast

persistence

$\mathrm{MV} \mathrm{HR}{ }^{*}$ for RFS with early blast

persistence

$1.42(1.18-1.71)$

$<0.001$

MV-HR* for EFS with early blast

persistence

$1.22(1.02-1.50)$

0.031

Combined remission prior to post-induction therapy

$\mathrm{N}$ (\% of group with post-induction combined remission)

$508(62)$

$1.34(1.13-1.59)$

0.001

OS (months), median $(95 \% \mathrm{Cl})$

RFS (months), median (95\% Cl)

$\mathrm{MV}-\mathrm{HR}^{*}$ for OS with early blast

persistence

$\mathrm{MV}-\mathrm{HR}^{\star}$ for RFS with early blast

persistence

MV CS-HR* for NRM with early

blast persistence

CS-HR ${ }^{\star}$ for relapse with early blast

persistence

\begin{tabular}{|c|c|c|}
\hline $508(62)$ & 305 (38) & \\
\hline $42.2(31.8-52.6)$ & 29.3 (20.7-37.8) & 0.016 \\
\hline $18.8(15.8-21.9-37.8)$ & $13.0(10.5-15.6)$ & 0.013 \\
\hline \multicolumn{2}{|c|}{$1.29(1.03-1.60)$} & 0.024 \\
\hline \multicolumn{2}{|c|}{$1.35(1.11-1.65)$} & 0.002 \\
\hline \multicolumn{2}{|c|}{$1.42(0.97-2.07)$} & 0.069 \\
\hline \multicolumn{2}{|c|}{$1.30(1.01-1.62)$} & 0.039 \\
\hline
\end{tabular}

*The multivariate analysis included the following dichotomized parameters: Eastern Cooperative Oncology Group score $\leq 1$ vs. $>1$, Charlson Comorbidity Index $<2$ vs. $\geq 2$, European LeukemiaNet risk group favorable vs. intermediate/adverse, age $<60$ years vs. $\geq 60$ years, subtype of acute myeloid leukemia de novo vs. secondary/therapy-related. CR: complete remission; CRi: complete remission with incomplete hematologic recovery; MLFS: morphological leukemia-free state; n: number of patients; PR: partial remission; AML: acute myeloid leukemia; 95\% Cl: 95\% confidence interval; OS: overall survival; EFS: event-free survival; RFS: relapse-free survival; MV: multivariate; HR: hazard ratio; NRM: non-relapse mortality; CS-HR: cause-specific hazard ratio. 


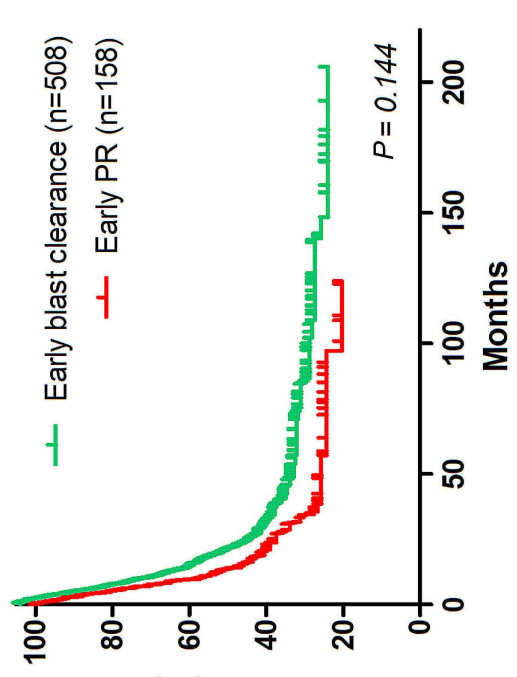

(\%) Sty

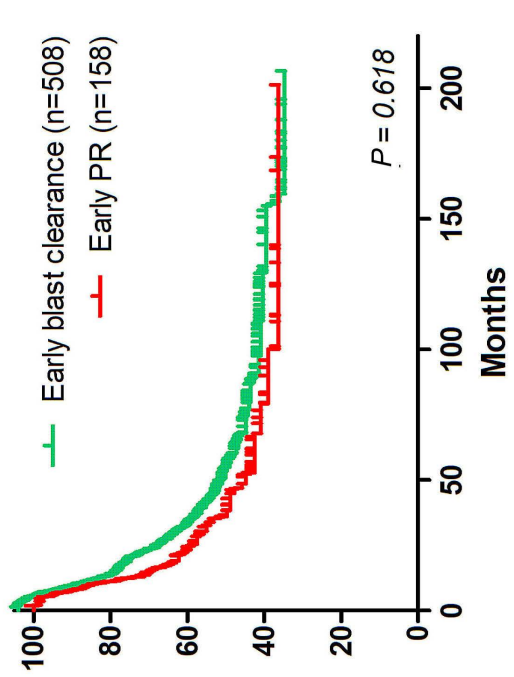

(\%) so

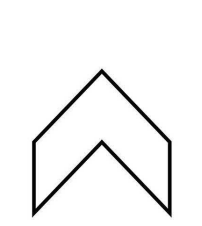

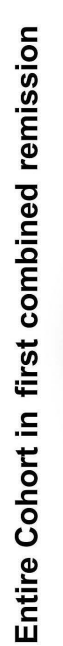

4

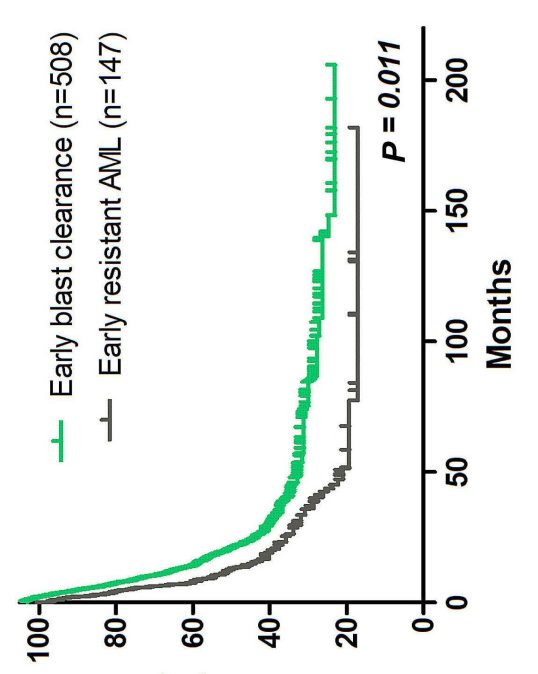

(\%) S거

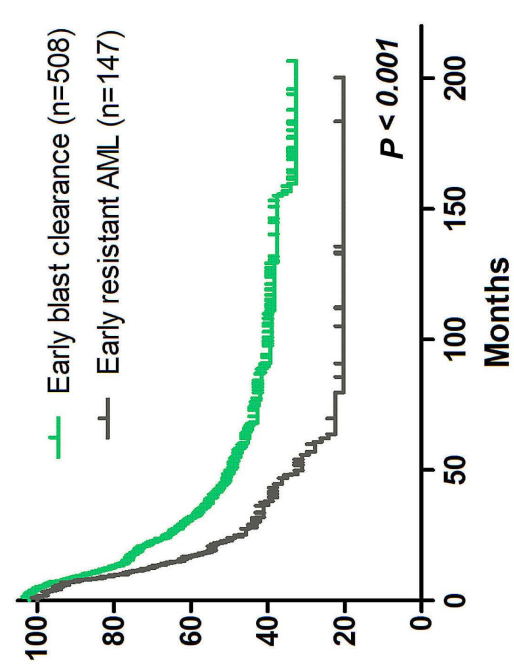

(\%) so
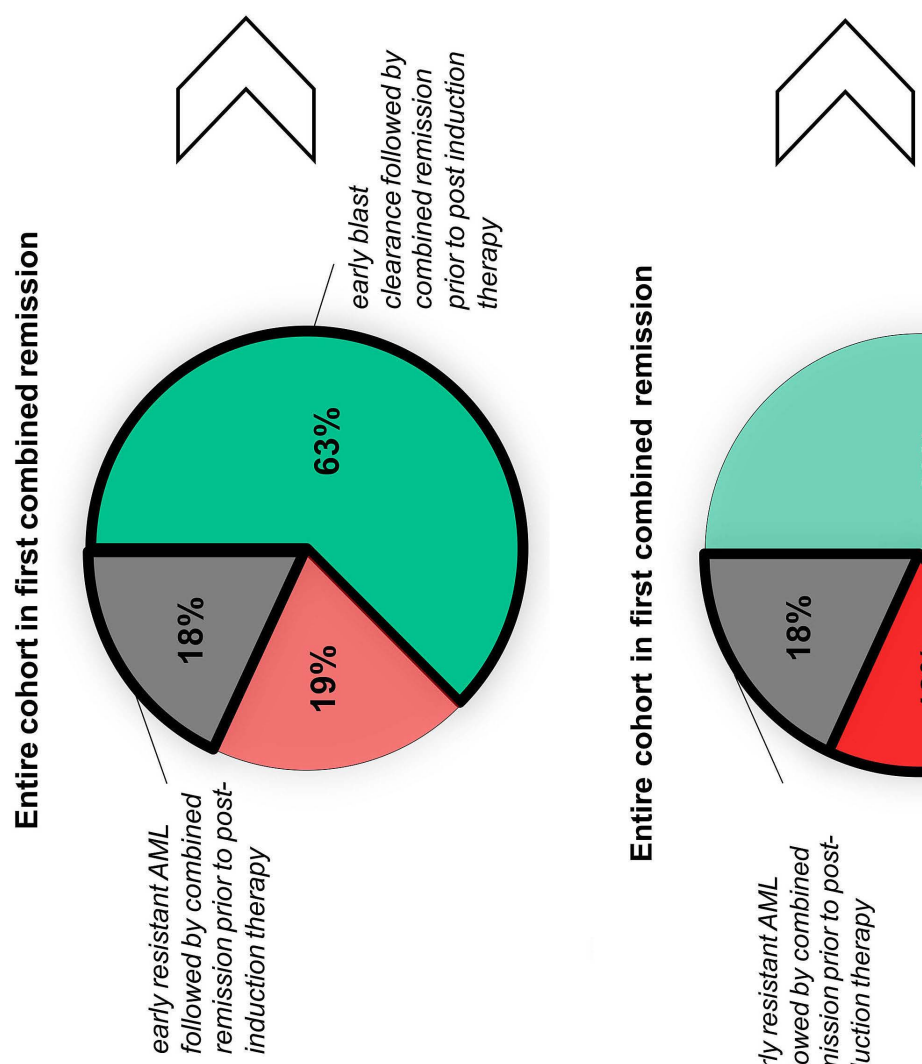

$\boldsymbol{m}$

(\%) S거

(\%) so

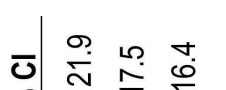

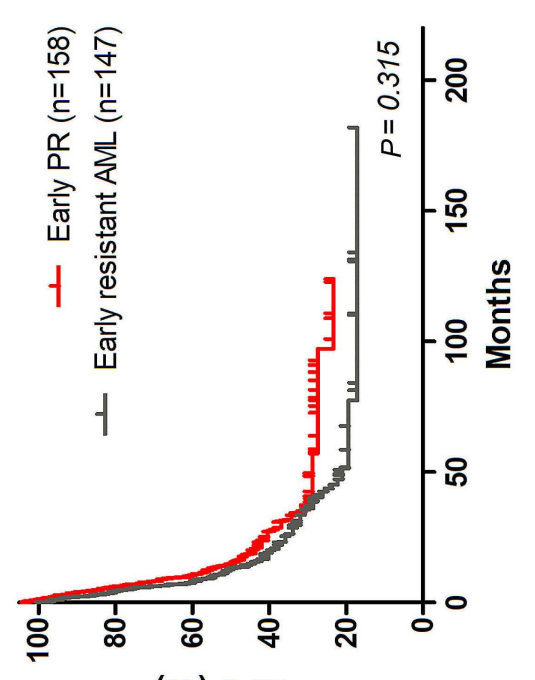

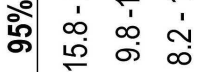
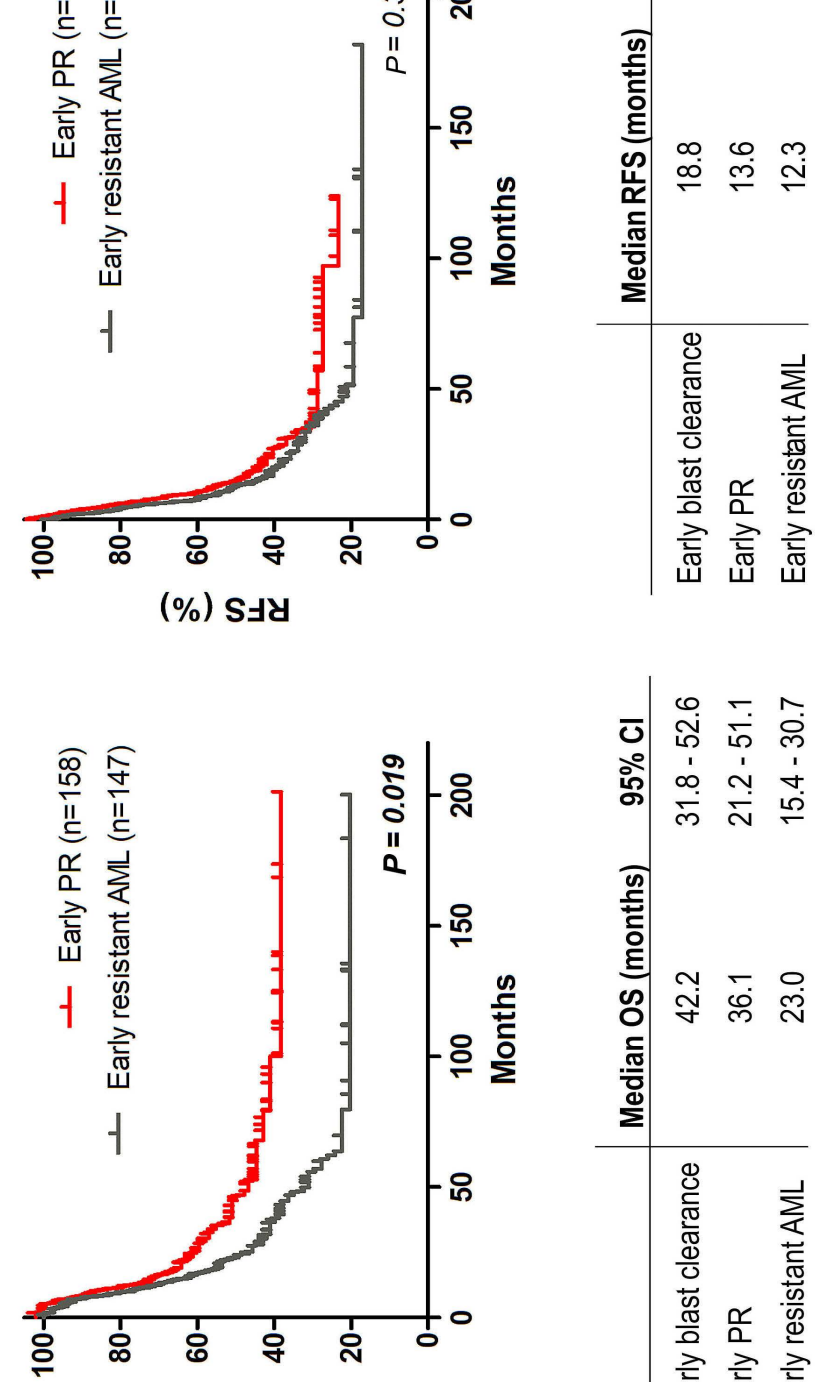

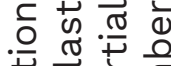

त

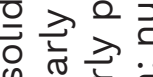

ก

ठํ.

o $3 \frac{1}{3} \frac{1}{3}$

늬 क ज

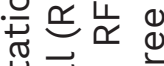

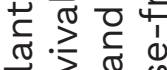

की

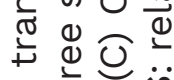

u

क क $\frac{\pi}{\varepsilon}$

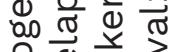

宁 过

$\therefore \div$ o

중 $\frac{0}{2}=$

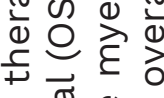

ত

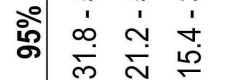

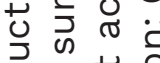

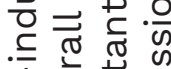

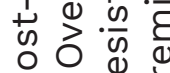

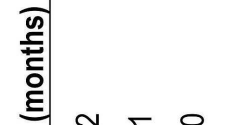

๓ี

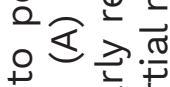

항

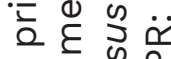

ᄃ की

in

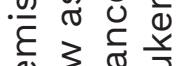

ब 3 䨌

要

交

高 峁

응을

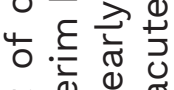

도도.

है⿴囗十)

$\underbrace{}_{\infty}$

d

ช

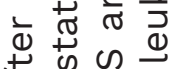

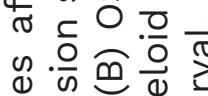

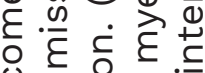

咭 Ф.

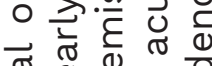

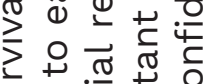

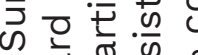

+

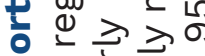

둥 ฮิ

○赵

䎡 원 ఏ ๓ं

m

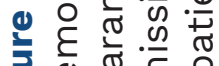

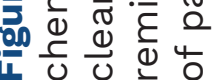


Prognostic impact of early blast clearance in patients who underwent allogeneic hematopoietic stem cell transplantation as post-remission therapy

Of all patients, 68\% $(687 / 1,008)$ underwent allogeneic HSCT. Among these transplanted patients, 5-year OS and RFS were $44 \%$ and $28 \%$, and median OS and RFS were 41.8 months (95\% Cl: 33.1-50.3 months) and 16.5 months (95\% Cl: 14.1-19.0 months), respectively. Of these patients, $58 \%$ (401/687) underwent allogeneic HSCT as consolidation therapy in first remission, whereas the remaining $42 \%$ $(286 / 687)$ received their transplant beyond first remission (Table 1).

Patients who underwent allogeneic HSCT in first remission ( $n=401)$ had a 5 -year OS of $51 \%$ and a 5 -year RFS of $47 \%$ with a median OS of 62.1 months (95\% Cl: 33.1-91.0 months) and a median RFS of 38.6 months (95\% Cl: 17.359.9 months). Regarding OS and RFS, there was no significant difference between patients with early blast clearance and early PR in this particular subset of patients (Figure 4A). In contrast, patients with early resistant AML showed both inferior RFS and OS, even after having achieved combined remission prior to allogeneic HSCT (Figure 4B). Precisely, 5-year OS was 57\% with early blast clearance, and $46 \%$ with early PR $(P=0.267)$ as compared to $37 \%$ with early resistant AML (Figure $4 B, C, P=0.002$ ). The 5 -year RFS was $51 \%$ with early blast clearance, $42 \%$ with early PR $(P=0.333)$ and $32 \%$ with early resistant $A M L$ $(P=0.001)$.

Considering the multivariate analysis, early resistant AML was an unfavorable prognostic factor in patients who underwent allogeneic HSCT as consolidation therapy (OS: $P=0.011, \mathrm{HR}=1.6,95 \% \mathrm{Cl}: 1.1-2.4$; RFS: $P=0.006, \mathrm{HR}=1.7,95 \%$ $\mathrm{Cl}: 1.2-2.4)$. In patients who had been transplanted in first remission, we further analyzed the influence of both the type of transplant conditioning (MAC Vs. RIC) and the type of donor (matched sibling donor [MSD] vs. matched unrelated donor [MUD]) on the clinical outcome. In fact, 136/401 patients received MAC, whereas 261/401 patients were treated with RIC (information on the conditioning regimen was not available in 4 cases). Comparing MAC and RIC, we found a significant difference in median OS (61.2 months vs. 46.8 months, $P=0.012)$ and RFS (58.4 months vs. 33.5 months, $P=0.013$ ). However, this finding was mainly attributable to major differences in median age (39 years vs. 58 years, $P<0.001)$ and Charlson Comorbidity Index (upper quartile 0 points vs. 1 point, $P<0.001$ ) between both groups. In contrast, ELN subgroups $(P=0.182)$ and median ECOG status $(P=0.866)$ did not differ significantly between patients given MAC or RIC. More importantly, there was no significant difference in early remission status between patients given MAC or RIC since early blast clearance and blast persistence were similarly distributed between these subgroups (early blast clearance $51 \%$ with MAC vs. $58 \%$ with RIC, early blast persist- ence $49 \%$ with MAC vs. $42 \%$ with RIC, $P=0.153$ ) and, vice versa, MAC and RIC application were equally distributed within the remission subgroups. Regarding the type of donor (MSD vs. MUD), there was a trend towards better OS and RFS in patients with MSD (OS 59.4 months vs. 47.0 months, $P=0.058$; RFS: 51.3 months vs. 34.3 months, $P=0.091)$ However, this seemed to be caused again by differences in median age (50 vs. 53 years, interquartile range 37-58 vs. 43-62 years, $P=0.003$ ) or HLA-mismatch (full match vs. mismatch, $P<0.001$ ). However, early blast clearance and blast persistence were equally distributed within the subgroups with MSD and MUD (early blast clearance: $56 \%$ with MSD and MUD, early blast persistence: $44 \%$ with MSD and MUD, $P=0.968$ ) and vice versa. In conclusion, early resistant AML remained an independent unfavorable prognostic factor in the multivariate analysis of patients with allogeneic HSCT as consolidation therapy (OS: $P=0.011, \mathrm{HR}=1.6,95 \% \mathrm{Cl}: 1.1-2.4$; RFS: $P=0.006$, $\mathrm{HR}=1.7,95 \% \mathrm{Cl}: 1.2-2.4)$.

\section{Prognostic impact of early blast persistence in patients} who received chemotherapy as post-remission therapy In patients who did not undergo allogeneic HSCT (321/1,008), 5-year OS and RFS were $20 \%$ and $17 \%$ with a median OS of 12.0 months (95\% Cl: 9.9-14.1 months) and a median RFS of 8.4 months (95\% Cl: 6.8-9.9 months). Fifty-one percent (165/321) of the non-transplanted patients had achieved blast clearance prior to consolidation chemotherapy. Of these latter patients, 24\% (39/165) had been treated with one cycle of induction chemotherapy and $76 \%(126 / 165)$ had received two cycles of induction therapy. Within the latter subgroup of non-transplanted patients who had received two cycles of induction therapy, 5 -year OS and RFS were $32 \%$ and $23 \%$ with a median OS and RFS of 17.8 months (95\% Cl: 9.5-26.1 months) and 9.7 months (95\% Cl: 6.9-12.5 months), respectively. In these patients, early blast clearance was comparable to early PR with regard to OS (5-year OS $40 \%$ vs. $32 \%$, $P=0.401$ ) (Figure $5 \mathrm{~A}$ ). In contrast, RFS with early PR was significantly worse than with early blast clearance in the univariate analysis (5-year RFS $32 \%$ vs. $15 \%, P=0.037$ ) (Figure $5 \mathrm{~A}$ ), and there was a clear trend towards inferior survival in the multivariate model $(\mathrm{HR}=1.6,95 \% \mathrm{Cl}: 1.0-2.7$, $P=0.058$ ), suggesting an adverse prognostic impact of early PR on RFS which was most likely compensated by subsequent salvage therapy with regard to OS.

\section{Discussion}

Whether an early remission during AML induction therapy is of any prognostic value has remained a matter of debate over the past decade. Even in the era of minimal/ measurable residual disease (MRD)-guided therapeutic decision- 


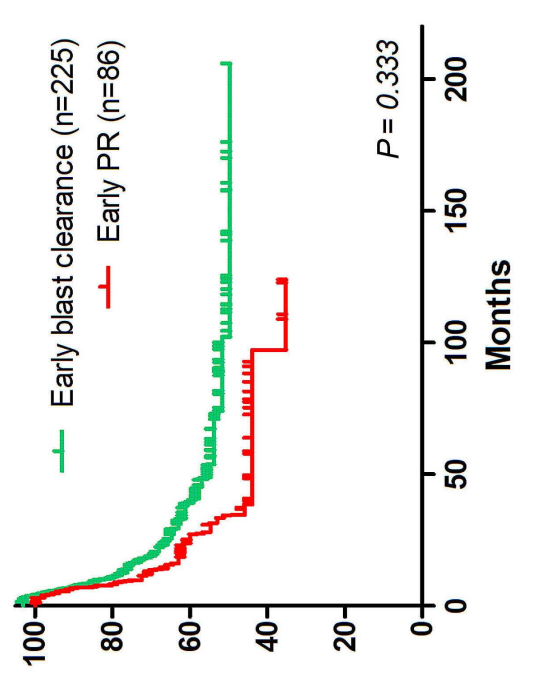

(\%) Sty

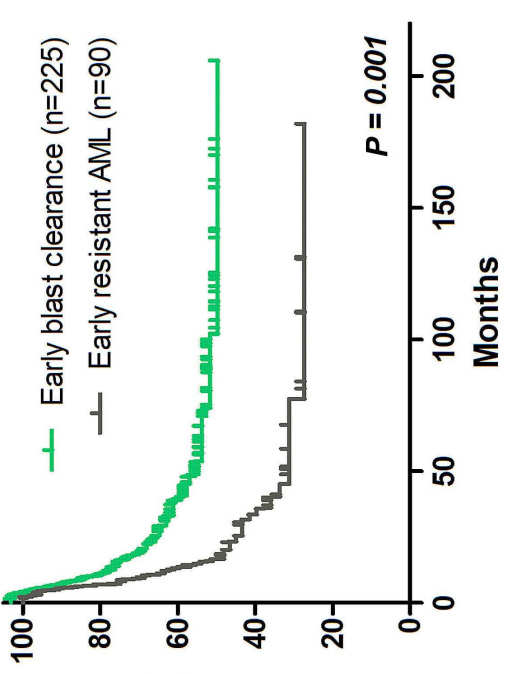

(\%) Sty

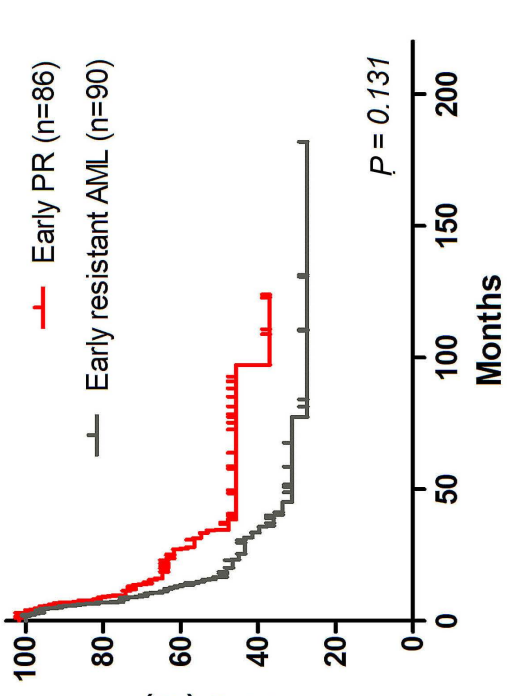

(\%) S与ل

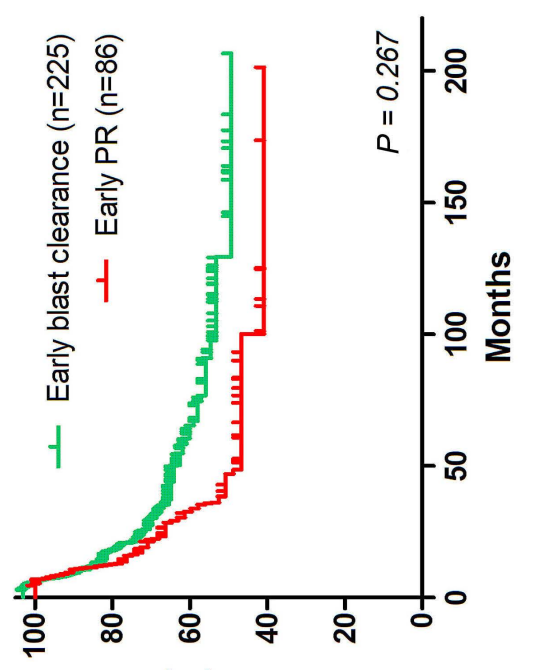

(\%) so

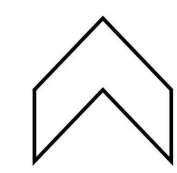

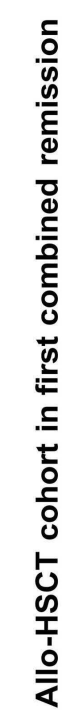

4

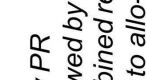

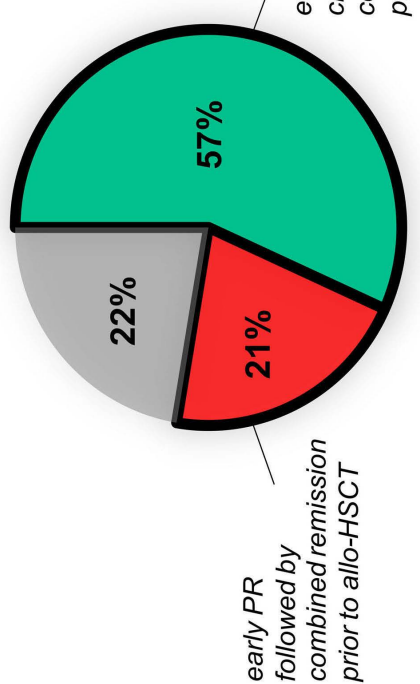

m

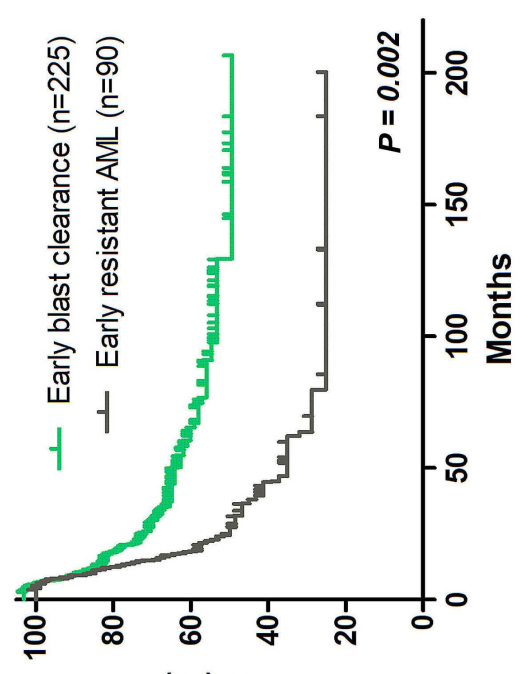

(\%) So

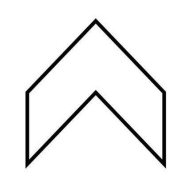

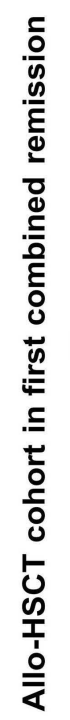

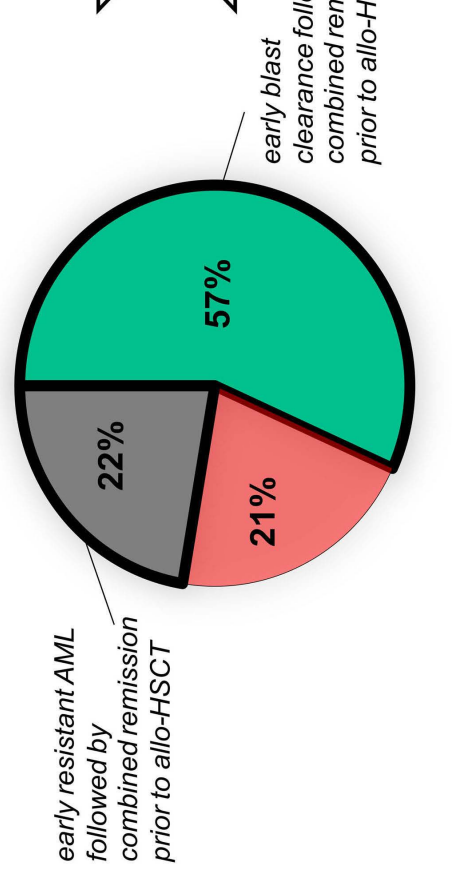

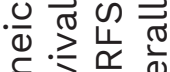

ه广

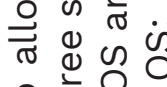

$+4 \begin{array}{ccc}4 & 0 \\ 1 & 0 & 0\end{array}$

可它蓆若

을

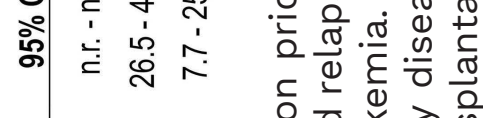

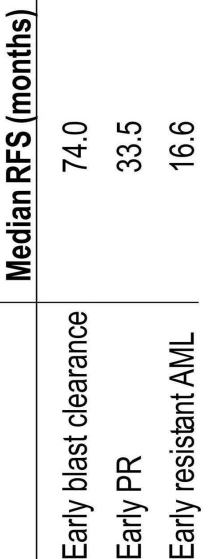

을

$\bar{\varepsilon} \overline{0}$

ब

웅

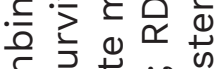

है क

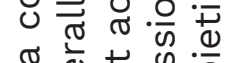

पे

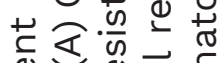

है+

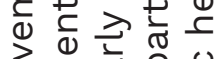

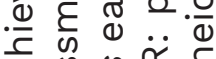

ত

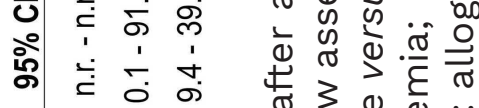

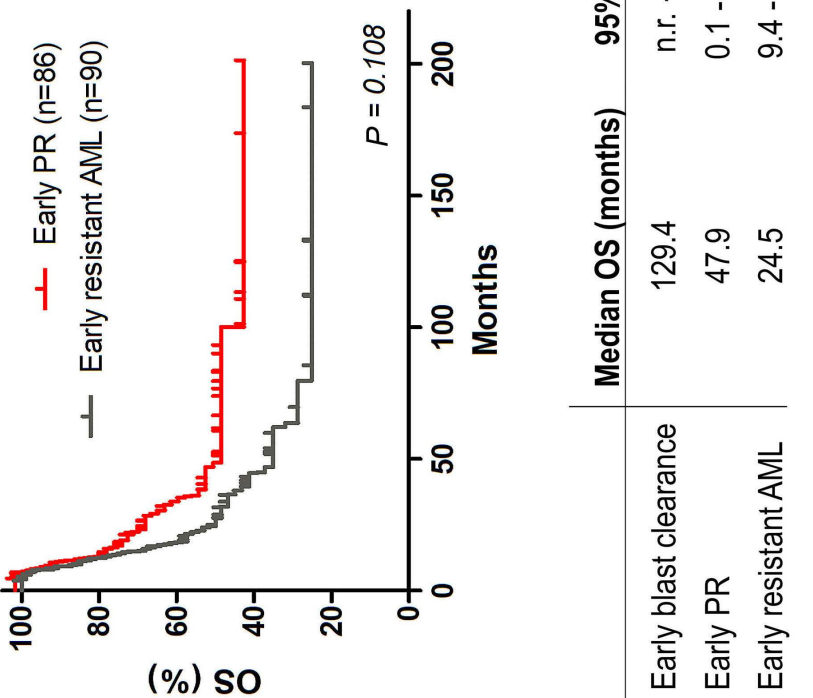

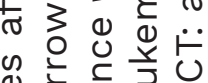

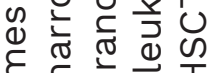

ร $\varepsilon$ đั

嵌

०

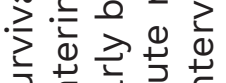

ज.

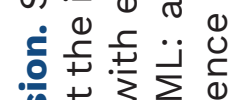

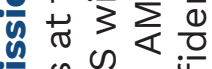

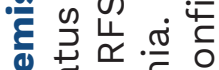

世

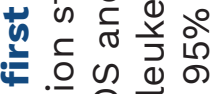

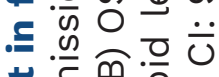

능 $\overline{\frac{0}{0}} \frac{0}{0}$

응 을 ญ

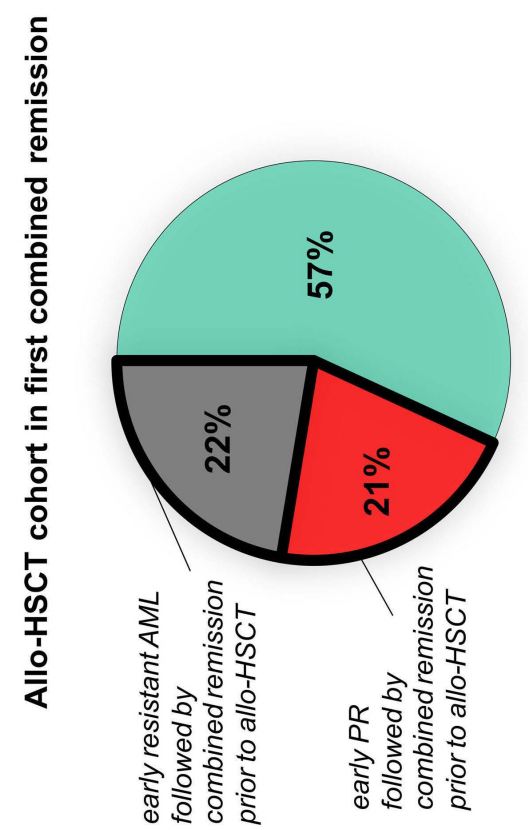

U ब.

สำ

흔휴

สำ

-

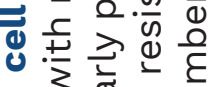

ร 3 ब

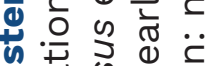

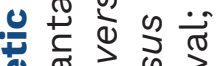

0 西 0

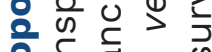

承

है월

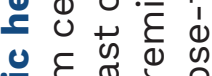

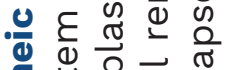

두에

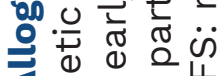

द $\frac{0}{0}$ 땀

ச่

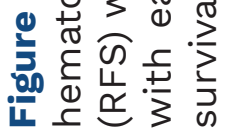




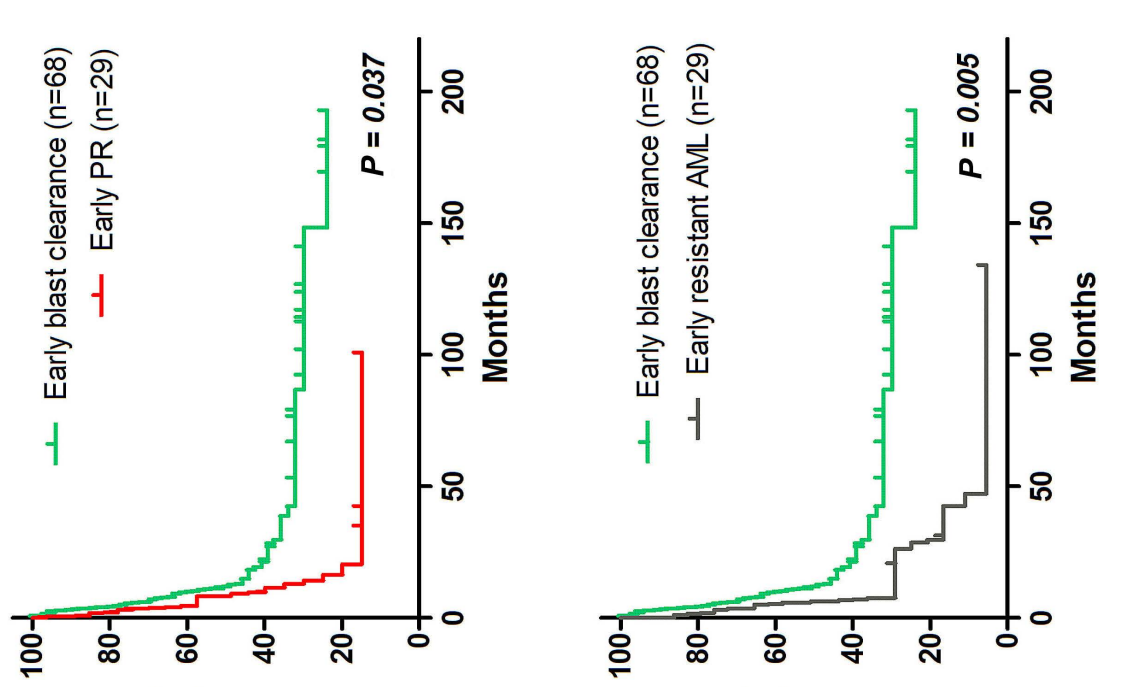

(\%) Sty

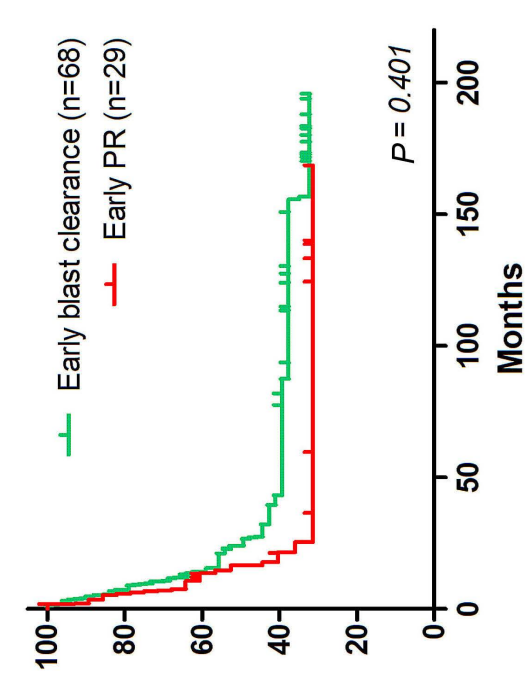

(\%) so
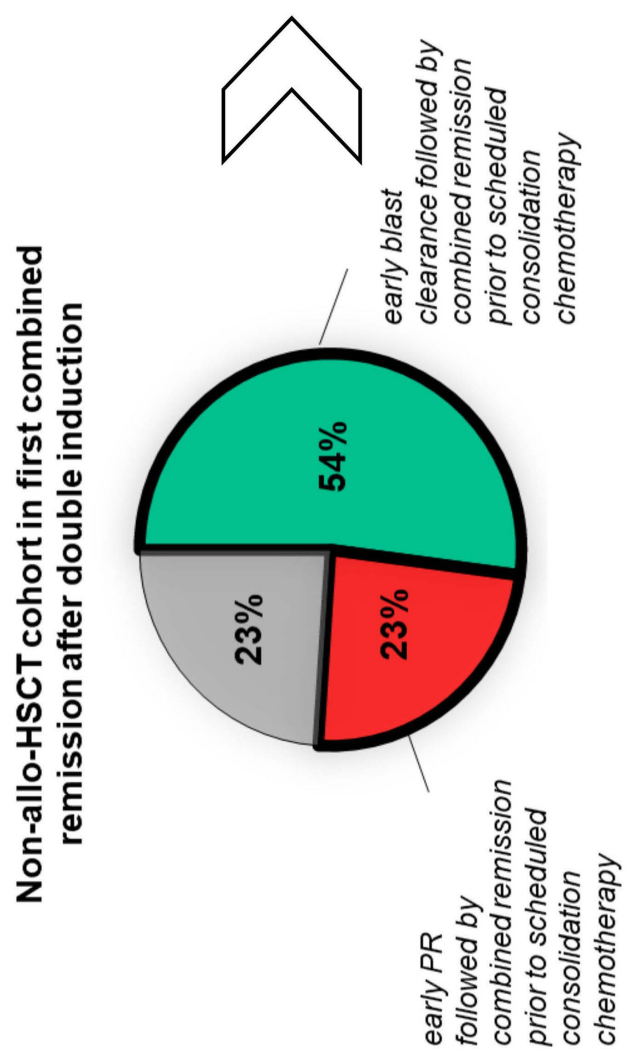

$\leftarrow$

(\%) Sty
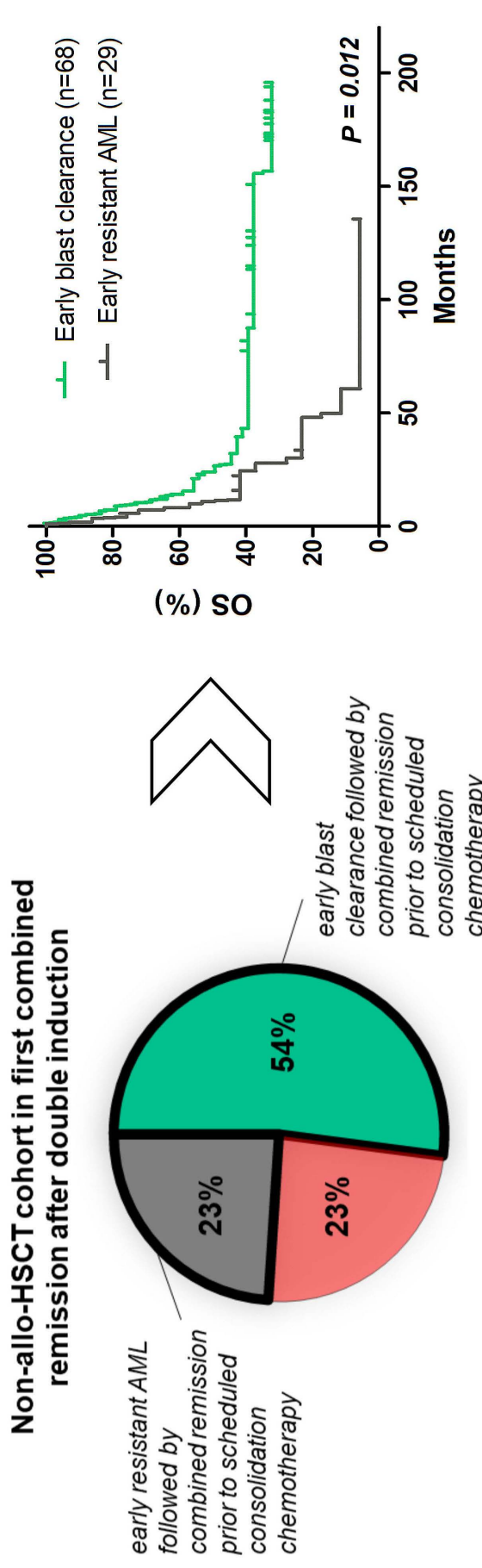
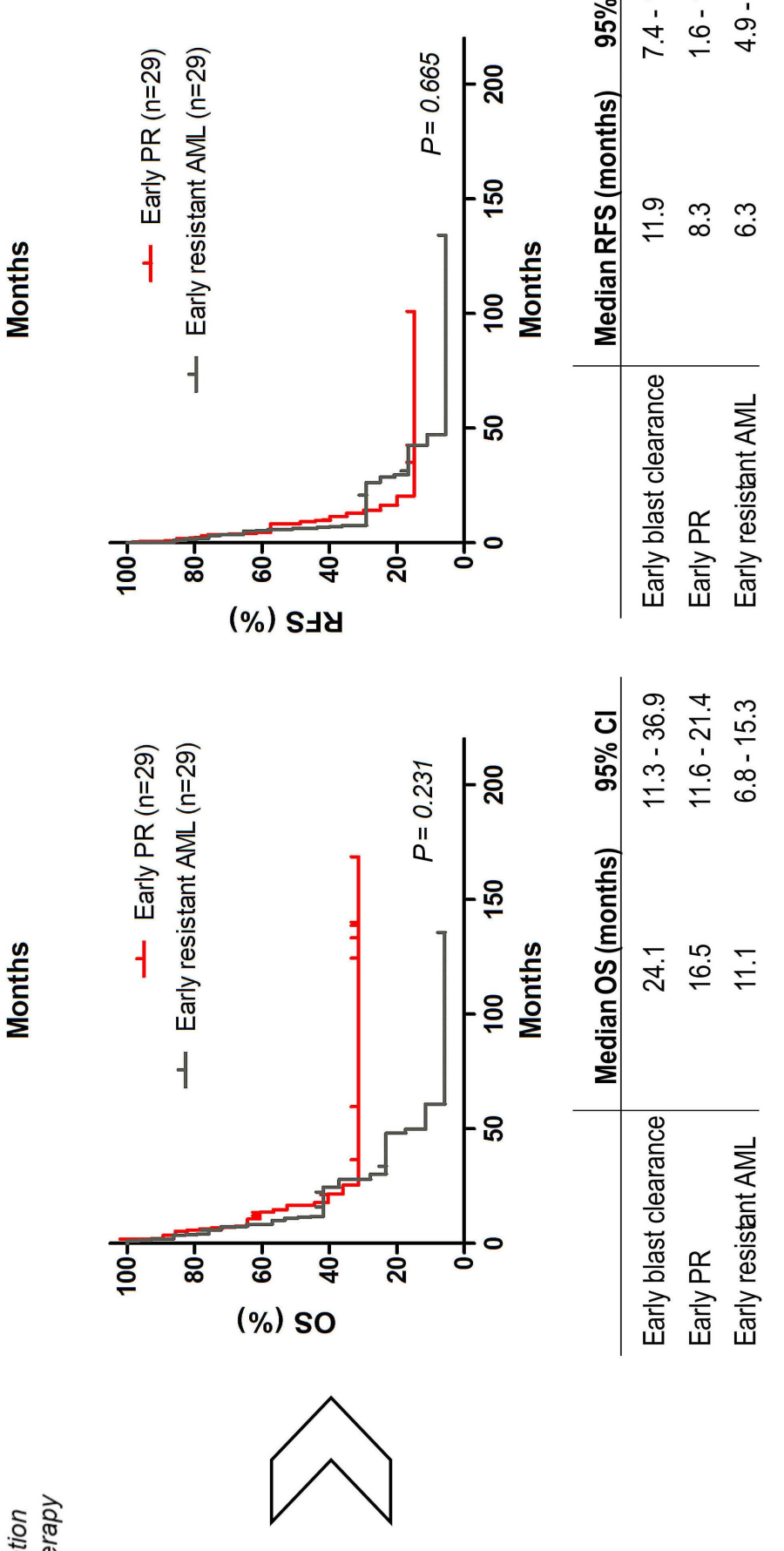

$\stackrel{\infty}{=} \infty_{\infty}^{\infty}$
(\%) Sty

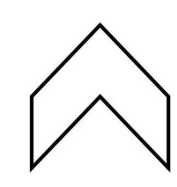

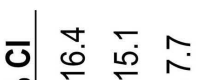

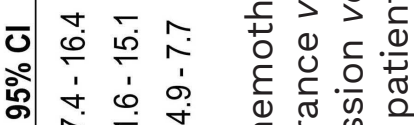

势然字

政

일

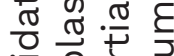

势

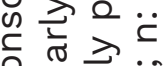

0 0 范

ब

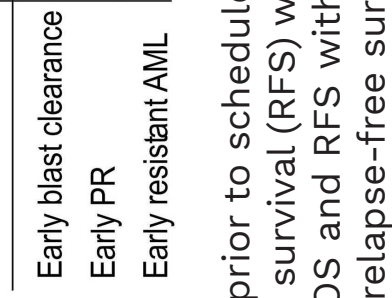

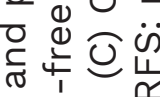

(d)

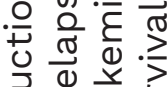

垔

(ब) $\bar{\sigma} \frac{\bar{\sigma}}{\bar{\sigma}}$

윽

응

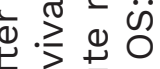

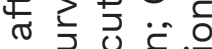

드 के

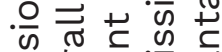

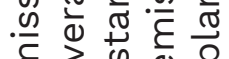

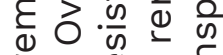

无电可

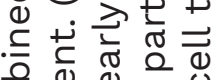

$\varepsilon \varepsilon$ थ $\ddot{\sim} \varepsilon$

O)

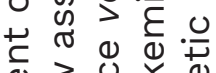

ब) 30

ह 이 ๘

ख

ป

बे О

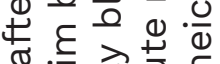

สั

立.

+்

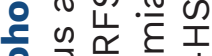

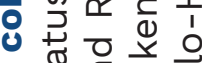

유

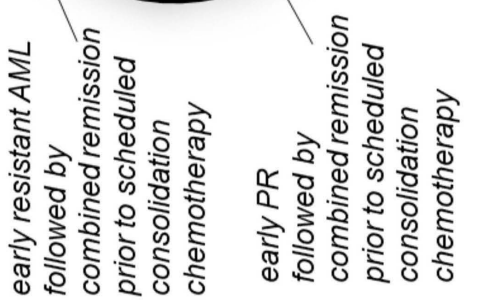

릉 ऽ

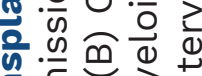
สิ

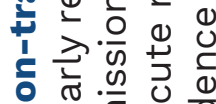

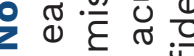
เค 어 이유

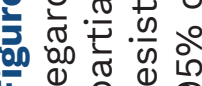


ACTUAL TREATMENT

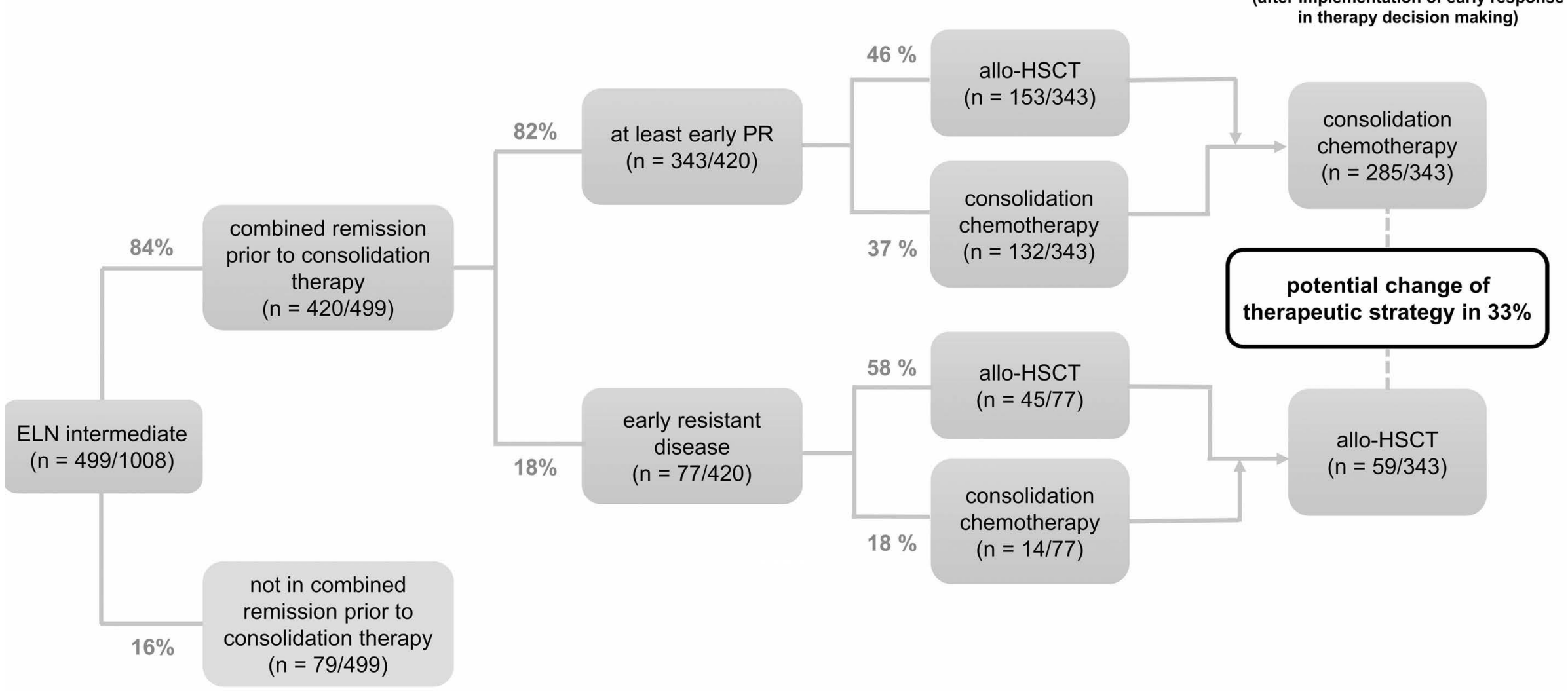

Figure 6. Potential treatment algorithm in European LeukemiaNet intermediate-risk acute myeloid leukemia after implementation of the early response as an additional prognostic parameter (in a notional scenario). Clinical responses and therapy decisions in 499 patients with intermediate-risk acute myeloid leukemia (according to the European LeukemiaNet classification) with and without implementation of the early bone marrow assessment into further therapeutic decision making. In our cohort, $153 / 343$ patients with at least an early partial remission underwent allogeneic hematopoietic stem cell transplantation (HSCT) and 132/343 were treated with consolidation chemotherapy. In these groups, the implementation of the early response as a prognostic parameter (in addition to minimal residual disease, which was not available in our cohort) would have possibly led to consolidation chemotherapy instead of allogeneic transplantation in $153 / 343$ patients, if they had achieved minimal residual disease negativity. Seventy-seven of 420 patients had early resistant disease. Within this subgroup, $45 / 77$ underwent allogeneic HSCT and 14/77 consolidation chemotherapy. The implementation of the early response as a prognostic parameter (in addition to minimal residual disease) would have possibly led to allogeneic HSCT as consolidation therapy in an additional $14 / 77$ patients. Thus, in our cohort, the implementation of early response would have possibly changed treatment decision in $33 \%$ of ELN intermediate-risk patients and in 17\% of all patients. ELN: European LeukemiaNet; n: number of patients; PR: partial remission; allo-HSCT: allogeneic hematopoietic stem cell transplantation.

making, this controversy has not been resolved, since early blast clearance can indicate a therapy response at a very early time point when MRD assessment is not yet part of the routine management. Furthermore, there are also patients in whom an adequate MRD marker cannot be established. In these cases, early BM assessment may inform therapeutic decision-making, particularly for those in whom the choice of consolidation therapy (i.e., conventional chemotherapy vs. allogeneic HSCT) is challenging. Over the past decade, there has been an extensive discussion not only on the general value, but also on the most appropriate time point, of the early BM assessment. Recommendations vary from omitting early BM assessment completely (due to a lack of prognostic information) to its implementation during induction therapy between day 6 and day 21.,5-9 At our institution, the early BM assessment was generally performed between day 14 and 21 , as previous studies had shown that there is no substantial difference between BM evaluation on day 14 and 21 and, thus, results obtained within this interval were merged. ${ }^{3,7}$ Certainly, there is some heterogeneity with re- gard to induction and consolidation therapy within our cohort of AML patients. However, the different treatment protocols were prospectively compared within the German Intergroup trial and no relevant outcome differences were detected ${ }^{22}$ and thus they should be comparable with regard to long-term survival.

Our large cohort of 1,008 intensively treated patients with newly diagnosed AML does now confirm a negative prognostic impact of early blast persistence on both OS and RFS. While in our cohort survival was slightly above the upper range of international studies, ${ }^{23,24}$ which might be explained by the large number of patients who underwent allogeneic HSCT, the survival in the transplanted cohort was in the range of other studies in AML. ${ }^{25-28}$

Thus, the favorable impact of early blast clearance observed in our cohort is in line with previously published data, ${ }^{1,12}$ and it seems conceivable that this effect is due to chemosensitivity of AML cells in vivo. Vice versa, the negative impact of early persistent AML most likely reflects resistance to conventional chemotherapy. ${ }^{13,15}$ This assumption is emphasized by the comparison of cause- 
specific hazards for relapse and non-relapse mortality in our cohort. When comparing patients with early blast persistence to patients with early blast clearance, we observed a significant increase in the risk of relapse, but not in the risk of non-relapse mortality. This finding strongly suggests that the unfavorable prognostic impact of early blast persistence is mainly driven by disease relapse and less by toxicity caused by additional therapy.

Interestingly, the achievement of a combined remission prior to post-induction therapy outperforms the negative impact of early blast persistence on OS, if the early BM assessment shows at least a PR. In contrast, the negative prognostic impact of early resistant AML cannot be completely overcome, even if a combined remission is obtained prior to consolidation therapy. Notably, in patients with a later combined remission during induction, the poor prognostic impact of early blast persistence can be in part compensated by consolidation with allogeneic HSCT. This is possibly due to an additional immunological graft-versus-leukemia-effect that may compensate for a lower extent of chemosensitivity in these cases. ${ }^{29-32}$ This hypothesis is underlined by the observation that the adverse prognostic impact of early blast persistence cannot be overcome in AML patients who do not proceed to allogeneic HSCT in first remission after induction therapy. Notably, early blast persistence only translates into inferior RFS in this subgroup, whereas OS is not significantly different, most likely because of subsequent salvage therapy.

There is general consensus on the key prognostic value of MRD both under intensive chemotherapy and in the setting of allogeneic HSCT. ${ }^{33-37}$ In addition, our study suggests that it is not only the static remission status at a particular time point after therapy, but also the time slope of remission which is of prognostic value. This seems reasonable since a rapid initial response (i.e., with early blast clearance on day 14-21) is a surrogate for chemo-responsiveness, whereas the need for a second induction cycle due to early blast persistence indicates at least some degree of chemoresistance. In this regard, it is intriguing that an early PR has a negative impact on RFS in non-transplant patients, whereas this is not observed in patients undergoing allogeneic HSCT. Therefore, early blast clearance from the BM can be considered a dynamic and easily attainable parameter indicative of therapeutic response in addition to the ELN risk stratification and MRD monitoring. This might primarily apply to patients within the intermediate ELN risk group (Figure 6) due to its biological heterogeneity and the challenging choice of the most appropriate consolidation treatment for individual patients in this subgroup. Potential risks and benefits of allogeneic HSCT need to be considered, such as the risk of relapse versus non-relpase mortality or treatment-related mortality. ${ }^{27,35,38-50}$ Interestingly, Venditti et al. recently showed in patients with intermediate-risk AML, according to the National Comprehensive Cancer Network (NCCN) classification, that consolidation with allogeneic HSCT in MRD-positive patients is practically equivalent to consolidation with autologous HSCT in patients who are MRDnegative. Using this strategy, the investigators found that disease-free survival in the group of intermediate-risk MRD-negative AML patients was comparable to that of NCCN favorable-risk AML patients. ${ }^{50}$ The important role of MRD stratification in intermediate-risk AML patients was also observed in a survey of the NCRI-AML17 trial. ${ }^{48}$ Thus, early treatment response (besides general health condition, MRD levels and donor availability) might serve as an additional parameter for risk stratification in intermediate-risk AML. In our cohort, such an early response assessment would have possibly influenced the post-induction therapy decision in approximately $33 \%$ of all ELN intermediate-risk patients (Figure 6).

Therefore, the adverse impact of early blast persistence might be overcome in the subgroup with at least an early PR by additional induction therapy resulting in subsequent remission prior to post-induction therapy that should comprise allogeneic HSCT consolidation. Unfortunately, MRD assessment by molecular methods and/or highly sensitive multicolor flow cytometry, particularly within the ELN intermediate-risk group, could not be included in our analysis, since these data were not available for all patients throughout the study period. In the future, additional evidence provided by large datasets from molecularly characterized AML cohorts consolidated with either intensive chemotherapy or allogeneic HSCT might pave the way for such a strategy which would then also need further prospective evaluation.

\section{Disclosures}

No conflicts of interest to disclose.

\section{Contributions}

$J I$ and $J W$ designed the study. AF, MS, NRN, AB, IA, ST, IWB, $T B, D H, L A B$ and JW performed the clinical and diagnostic workup required for this study. JI, SG, LEB and JW collected, analyzed, and interpreted the data. JI and JW wrote the manuscript draft. All authors critically revised the manuscript and approved the final version.

\section{Acknowledgments}

We thank Margrit Stodder, Alma Herneth, Kacper Adamiak and Annabel Sick for their administrative support. Furthermore, we owe thanks to Sven Bischoff for his excellent support with the statistical analysis.

\section{Data-sharing statement}

Data for this study are not publicly available due to ethical restrictions. 


\section{References}

1. Campuzano-Zuluaga G, Deutsch $Y$, Salzberg M, et al. Routine interim disease assessment in patients undergoing induction chemotherapy for acute myeloid leukemia: can we do better? Am J Hematol. 2016;91(3):277-282.

2. Döhner H, Estey E, Grimwade D, et al. Diagnosis and management of AML in adults: 2017 ELN recommendations from an international expert panel. Blood. 2017;129(4):424-447.

3. Yanada M, Borthakur G, Ravandi F, Bueso-Ramos C, Kantarjian H, Estey E. Kinetics of bone marrow blasts during induction and achievement of complete remission in acute myeloid leukemia. Haematologica. 2008;93(8):1263-1265.

4. National Comprehensive Cancer Network Clinical Practice Guidelines in Oncology (NCCN Guidelines): Acute Myeloid Leukemia. Version 1 (2017), available at: https://www.nccn.org/professionals/physician_gls/pdf/aml.pdf., date accessed: 03.09.2021

5. Percival M-E, Lai C, Estey E, Hourigan CS. Bone marrow evaluation for diagnosis and monitoring of acute myeloid leukemia. Blood Rev. 2017;31(4):185-192.

6. Griffin PT, Komrokji RS, Sweet K, et al. Bone marrow cellularity at day 14 is the most important predictive factor for response in patients with AML who require double-induction chemotherapy: analysis from a large, single institution experience. Am J Hematol. 2017;92(3):232-237.

7. Pullarkat V, Aldoss I. Prognostic and therapeutic implications of early treatment response assessment in acute myeloid leukemia. Crit Rev Oncol Hematol. 2015;95(1):38-45.

8. Ofran Y, Leiba R, Ganzel C, et al. Prospective comparison of early bone marrow evaluation on day 5 versus day 14 of the " $3+$ 7 " induction regimen for acute myeloid leukemia. Am J Hematol. 2015;90(12):1159-1164.

9. Alsaleh K, Aleem A, Almomen A, Anjum F, Alotaibi GS. Impact of day 14 bone marrow biopsy on re-induction decisions and prediction of a complete response in acute myeloid leukemia cases. Asian Pac J Cancer Prev. 2018;19(2):421-425.

10. Rowe JM, Kim HT, Cassileth PA, et al. Adult patients with acute myeloid leukemia who achieve complete remission after 1 or 2 cycles of induction have a similar prognosis: a report on 1980 patients registered to 6 studies conducted by the Eastern Cooperative Oncology Group. Cancer. 2010;116(21):5012-5021.

11. Terry CM, Shallis RM, Estey E, Lim SH. Day 14 bone marrow examination in the management of acute myeloid leukemia. Am J Hematol. 2017;92(10):1079-1084.

12. Kern W, Haferlach T, Schoch C, et al. Early blast clearance by remission induction therapy is a major independent prognostic factor for both achievement of complete remission and longterm outcome in acute myeloid leukemia: data from the German AML Cooperative Group (AMLCG) 1992 Trial. Blood. 2003;101(1):64-70.

13. Hussein K, Jahagirdar B, Gupta P, Burns L, Larsen K, Weisdorf D. Day 14 bone marrow biopsy in predicting complete remission and survival in acute myeloid leukemia. Am $\mathrm{J}$ Hematol. 2008;83(6):446-450.

14. Estey E Shen Y, Thall PF. Effect of time to complete remission on subsequent survival and disease-free survival time in $A M L$, RAEB-t, and RAEB. Blood. 2000;95(1):72-77.

15. Bertoli S, Bories P, Béné MC, et al. Prognostic impact of day 15 blast clearance in risk-adapted remission induction chemotherapy for younger patients with acute myeloid leukemia: long-term results of the multicenter prospective LAM-2001 trial by the GOELAMS study group. Haematologica.
2014;99(1):46-53.

16. Döhner H, Estey EH, Amadori S, et al. Diagnosis and management of acute myeloid leukemia in adults: recommendations from an international expert panel, on behalf of the European LeukemiaNet. Blood. 2010;115(3):453-474.

17. Oken MM, Creech RH, Tormey DC, et al. Toxicity and response criteria of the Eastern Cooperative Oncology Group. Am J Clin Oncol. 1982;5(6):649-656.

18. Charlson ME, Pompei P, Ales KL, MacKenzie CR. A new method of classifying prognostic comorbidity in longitudinal studies: development and validation. J Chron Dis. 1987;40(5):373-383.

19. Cheson BD, Bennett JM, Kopecky KJ, et al. Revised recommendations of the International Working Group for Diagnosis, Standardization of Response Criteria, Treatment Outcomes, and Reporting Standards for Therapeutic Trials in Acute Myeloid Leukemia. J Clin Oncol. 2003;21(24)4642-4649.

20. lacobelli $S$, on behalf of the ESC. Suggestions on the use of statistical methodologies in studies of the European Group for Blood and Marrow Transplant. Bone Marrow Transplant. 2013;48(1):S1-S37.

21. Andersen PK, Geskus RB, de Witte T, Putter H. Competing risks in epidemiology: possibilities and pitfalls. Intern $\mathrm{J}$ Epidemiol. 2012;41(3):861-870.

22. Büchner T, Schlenk RF, Schaich M, et al. Acute myeloid leukemia (AML): different treatment strategies versus a common standard arm--combined prospective analysis by the German AML Intergroup. J Clin Oncol. 2012;30(29):3604-3610.

23. Howlader N NA, Krapcho M, Miller D, et al. SEER Cancer Statistics Review, 1975-2013, National Cancer Institute. Bethesda, MD, available from: http://seer.cancer.gov/csr/1975_2013/, based on November 2015 SEER data submission, posted to the SEER web site, 04. 2016. date accessed:03.09.2021

24. Song $X$, Peng $Y$, Wang $X$, et al. Incidence, survival, and risk factors for adults with acute myeloid leukemia not otherwise specified and acute myeloid leukemia with recurrent genetic abnormalities: analysis of the Surveillance, Epidemiology, and End Results (SEER) database, 2001-2013. Acta Haematol. 2018;139(2):115-127.

25. Shimoni A, Labopin M, Savani B, et al. Long-term survival and late events after allogeneic stem cell transplantation from HLAmatched siblings for acute myeloid leukemia with myeloablative compared to reduced-intensity conditioning: a report on behalf of the acute leukemia working party of European group for blood and marrow transplantation. J Hematol Oncol. 2016;9(1):118.

26. Bertoli S, Tavitian S, Huynh A, et al. Improved outcome for AML patients over the years 2000-2014. Blood Cancer J. 2017;7(12):635.

27. Koreth J, Schlenk R, Kopecky KJ, et al. Allogeneic stem cell transplantation for acute myeloid leukemia in first complete remission: systematic review and meta-analysis of prospective clinical trials. JAMA. 2009;301(22):2349-2361.

28. Schlenk RF, Döhner K, Mack S, et al. Prospective evaluation of allogeneic hematopoietic stem-cell transplantation from matched related and matched unrelated donors in younger adults with high-risk acute myeloid leukemia: German-Austrian trial AMLHD98A. J Clin Oncol. 2010;28(30):4642-4648.

29. Martino R, Caballero MaD, Perez Simon JA, et al. Evidence for a graft-versus-leukemia effect after allogeneic peripheral blood stem cell transplantation with reduced-intensity conditioning in 
acute myelogenous leukemia and myelodysplastic syndromes. Blood. 2002;100(6):2243-2245.

30. Sweeney C, Vyas P. The graft-versus-leukemia effect in AML. Front Oncol. 2019;9:1217.

31. Weisdorf D, Zhang M-J, Arora M, Horowitz MM, Rizzo JD, Eapen M. Graft-versus-host disease induced graft-versus-leukemia effect: greater impact on relapse and disease-free survival after reduced intensity conditioning. Biol Blood Marrow Transplant. 2012;18(11):1727-1733.

32. Gale RP, Horowitz HM. Graft-versus-leukemia in bone marrow transplantation. The Advisory Committee of the International Bone Marrow Transplant Registry. Bone Marrow Transplant. 1990;6(Suppl 1):94-97.

33. Schuurhuis GJ, Heuser M, Freeman S, et al. Minimal/measurable residual disease in AML: a consensus document from the European LeukemiaNet MRD Working Party. Blood. 2018;131(12):1275-1291.

34. Jongen-Lavrencic M, Grob T, Hanekamp D, et al. Molecular minimal residual disease in acute myeloid leukemia. N Engl $J$ Med. 2018;378(13):1189-1199.

35. Balsat M, Renneville A, Thomas X, et al. Postinduction minimal residual disease predicts outcome and benefit from allogeneic stem cell transplantation in acute myeloid leukemia with NPM1 mutation: a study by the Acute Leukemia French Association Group. J Clin Oncol. 2016;35(2):185-193.

36. Goldberg AD, Famulare C, Devlin SM, et al. Molecular predictors and current management of minimal residual disease (MRD) following induction chemotherapy for acute myeloid leukemia (AML). Blood. 2018;132(Suppl 1):292-292.

37. Kayser S, Benner A, Thiede C, et al. Pretransplant NPM1 MRD levels predict outcome after allogeneic hematopoietic stem cell transplantation in patients with acute myeloid leukemia. Blood Cancer J. 2016;6(7):e449.

38. Li D, Wang L, Zhu H, Dou L, et al. Efficacy of allogeneic hematopoietic stem cell transplantation in intermediate-risk acute myeloid leukemia adult patients in first complete remission: a meta-analysis of prospective studies. PLoS One. 2015;10(7):e0132620.

39. Suciu S, Mandelli F, de Witte T, et al. Allogeneic compared with autologous stem cell transplantation in the treatment of patients younger than 46 years with acute myeloid leukemia (AML) in first complete remission (CR1): an intention-to-treat analysis of the EORTC/GIMEMAAML-10 trial. Blood. 2003;102(4):1232-1240.
40. Slovak ML, Kopecky K, Cassileth PA, et al. Karyotypic analysis predicts outcome of preremission and postremission therapy in adult acute myeloid leukemia: a Southwest Oncology Group/Eastern Cooperative Oncology Group study. Blood. 2000;96(13):4075-4083.

41. Cornelissen JJ, van Putten WLJ, Verdonck LF, et al. Results of a HOVON/SAKK donor versus no-donor analysis of myeloablative HLA-identical sibling stem cell transplantation in first remission acute myeloid leukemia in young and middle-aged adults: benefits for whom? Blood. 2007;109(9):3658-3666.

42. Yanada M, Matsuo K, Emi N, Naoe T. Efficacy of allogeneic hematopoietic stem cell transplantation depends on cytogenetic risk for acute myeloid leukemia in first disease remission. Cancer. 2005;103(8):1652-1658.

43. Brunet S, Esteve J, Berlanga J, et al. Treatment of primary acute myeloid leukemia: results of a prospective multicenter trial including high-dose cytarabine or stem cell transplantation as post-remission strategy. Haematologica. 2004;89(8):940-949.

44. Tsimberidou A-M, Stavroyianni N, Viniou N, et al. Comparison of allogeneic stem cell transplantation, high-dose cytarabine, and autologous peripheral stem cell transplantation as postremission treatment in patients with de novo acute myelogenous leukemia. Cancer. 2003;97(7):1721-1731.

45. Pfirrmann M, Ehninger G, Thiede C, et al. Prediction of postremission survival in acute myeloid leukaemia: a post-hoc analysis of the AML96 trial. Lancet Oncol. 2012;13(2):207-214.

46. Stelljes M, Krug U, Beelen DW, et al. Allogeneic transplantation versus chemotherapy as postremission therapy for acute myeloid leukemia: a prospective matched pairs analysis. J Clin Oncol. 2014;32(4):288-296.

47. Burnett AK, Wheatley K, Goldstone AH, et al. The value of allogeneic bone marrow transplant in patients with acute myeloid leukaemia at differing risk of relapse: results of the UK MRC AML 10 trial. Br J Haematol. 2002;118(2):385-400.

48. Freeman SD, Hills RK, Virgo P, et al. Measurable residual disease at induction redefines partial response in acute myeloid leukemia and stratifies outcomes in patients at standard risk without NPM1 mutations. J Clin Oncol. 2018;36(15):1486-1497.

49. Ivey A, Hills RK, Simpson MA, et al. Assessment of minimal residual disease in standard-risk AML. N Engl J Med. 2016;374(5):422-433.

50. Venditti A, Piciocchi A, Candoni A, et al. GIMEMA AML1310 trial of risk-adapted, MRD-directed therapy for young adults with newly diagnosed acute myeloid leukemia. Blood. 2019;134(12):935-945. 